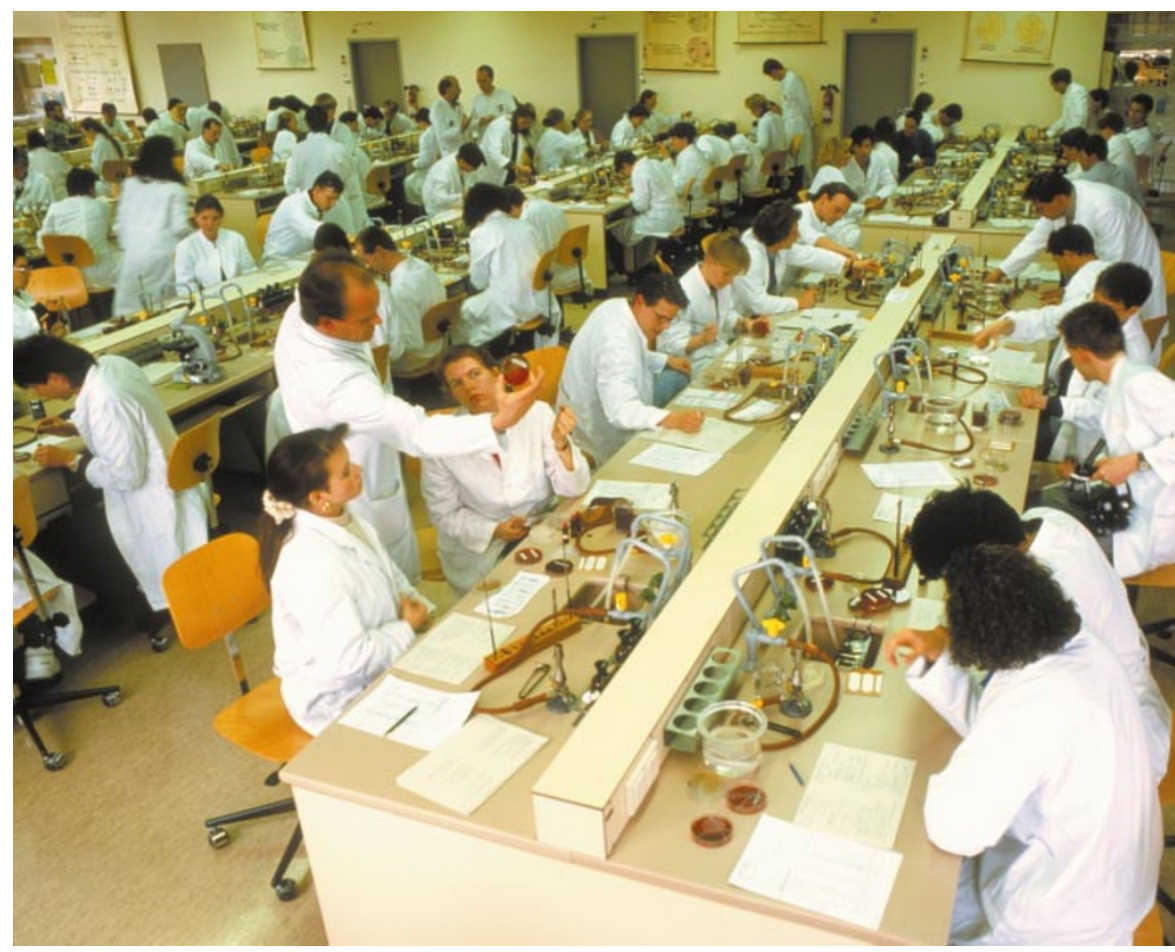

\title{
The youth team
}

\section{Undergraduates are not only writing scientific papers - they're reviewing them, editing them and posting them online. Josette Chen examines a scientific publishing phenomenon.}

$\mathrm{T}$ rying to get your first research paper published can be a daunting experience. After writing and revising ad infinitum, you finally submit to a leading journal - only to have your self-esteem crushed by a scathing referee's report. Wouldn't it have been better to hone your paper-writing skills while you were still an undergraduate, learning the tricks of the trade with help from your peers?

That is the thinking behind a crop of student journals that has emerged in the past few years. Set up to publish the results of undergraduate research projects, some of these operate solely online, avoiding the high production costs of print publications. Several are run entirely by undergraduates, with their editorial staff recruited from student ranks. And, like journals such as Nature, some even include news, comment and feature articles, in addition to publishing original research. Together, they are providing valuable experience in all aspects of scientific publishing for the researchers, journal editors and science writers of tomorrow.

Leading the pack is the international webbased Journal of Young Investigators (JYI), which has published three issues in the past couple of years, and is now gearing up to a regular output of three issues per year. It has an editorial staff of around 30 part-time undergraduate volunteers. Submitted manuscripts are reviewed by associate editors in conjunction with their faculty advisers. Recommendations are passed to section editors, who deal with different disciplines, and ultimately to the editor-in-chief - currently Courtney Peterson, who studies physics and biology at Georgetown University in Washington. "We try to get each manuscript through the whole process in five weeks," she says.

The JYI began in 1997 as a twinkle in the eyes of five undergraduates from Duke Uni-

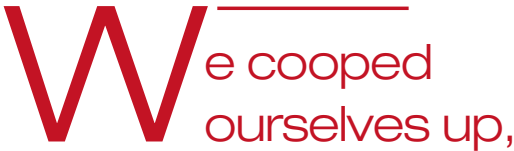
eating cold Chinese food, to come up with our mission statement. versity in Durham, North Carolina, Swarthmore College in Pennsylvania and Brown University in Providence, Rhode Island. Neal Freedman, George Lui, Andrew MedinaMarino, Tim Sibley and Brian Su felt that research by undergraduates was not getting due recognition and decided to remedy the situation. "We gathered in a Baltimore hotel and cooped ourselves up for two and a half days, eating cold Chinese food, to come up with our mission statement and budget," recalls $\mathrm{Su}$, now a medical student at Columbia University in New York, but then studying biomedical and electrical engineering at Duke.

The five students reckoned it would take at least $\$ 20,000$ to launch an online journal. "We just started laughing," says Su. “This is a huge sum for undergraduates." But the idea was warmly received, and after a year, $\mathrm{Su}$ and his colleagues had raised around $\$ 200,000$ from the National Science Foundation (NSF), the Burroughs Wellcome Fund, Glaxo Wellcome, Duke and Swarthmore. Through mass e-mailings and campus visits, the team recruited editors and solicited submissions - eventually going live with the journal's first issue in December 1998.

\section{Boundless enthusiasm}

There have been growing pains, mostly associated with the logistics of dealing with a dispersed staff working on a volunteer basis, with a high turnover rate. And one mathematics paper, outlining a proof for the irrationality of Euler's constant, was withdrawn after a former section editor spotted errors in the published version. But with plenty of e-mail and phone contact, yearly editorial conferences, and boundless enthusiasm, many of the wrinkles have been ironed out. The journal's founders, and many former staff, are continuing to share their experiences through the JYI's Board of Advisors. Peterson believes the quality of submissions is improving. And with her current staff, she is now finalizing the JYI's second NSF grant application, for around $\$ 100,000$.

The journal is also expanding internationally. Andreas Bender, who is studying chemistry at the Technical University of Berlin, joined the JYI early last year with a mandate to add European papers and staff. He has recruited James O’Dywer from Durham University in Britain as a section editor for physical sciences and mathematics.

Budding scientists who have published in the JYI are overwhelmingly positive about the experience. Elise Donnelly, who studied biology at the College of William and Mary in Williamsburg, Virginia, published a paper in the JYI's first issue on nest defence in blueheaded vireos (Vireo solitarius), birds in which both sexes play equal roles in parenting. Now finishing a masters programme at Wake Forest University in Winston-Salem, North Carolina, and planning for a $\mathrm{PhD}$ at the University of California, Santa Cruz, 


\section{ellow \\ undergraduates}

are more understanding than major figures in the field.

Donnelly says that writing her JYI paper helped build her skills and confidence. She is now preparing two papers for front-line journals. "People who've read the drafts say my writing is good," she says.

Brian Skotko of Duke University worked on a Howard Hughes Medical Institute undergraduate research fellowship in neuroscience, studying the effect of the nucleoside adenosine in a region of the rat hippocampus involved with processing spatial memory. After completing his final report, he submitted his work to the JYI. "I really got to learn science methodology, such as making hypotheses, solving problems and answering questions," says Skotko, who now plans to enter medical school.

Even though the JYI's review process is tough — only around $10 \%$ of the 200 -plus submissions received so far have been accepted for publication - its editors believe it provides a gentle introduction to getting a paper published. "You are being reviewed by fellow undergraduates, who are more understanding than major figures in the field," says Mary Patyten, a JYI associate editor.

\section{Gains all round}

The JYI has also provided valuable experience for its staff. Adam Friedman, now in his final year of a biology degree at Princeton University in New Jersey, says that editing other people's work has made him more critical of his own writing and how he presents his science. And Patyten, who helped develop JYI's features content while studying Earth systems science and policy at California State University, Monterey Bay, is now a science writer with the California Department of Fish and Game in Marina. The journal's staff can stay on for a year after they graduate, and Patyten is using that time to run a mentoring programme for aspiring science journalists who want to contribute to the JYI.

The JYI is just the most prominent of a string of student journals to have emerged in the past few years. Many are associated with particular universities, and publish the work of their host institutions' students. They follow in a long tradition: the University of Toronto Medical Journal, which is studentrun, was first published in 1923. But the potential for affordable scientific publication offered by the Internet has encouraged the launch of many others.

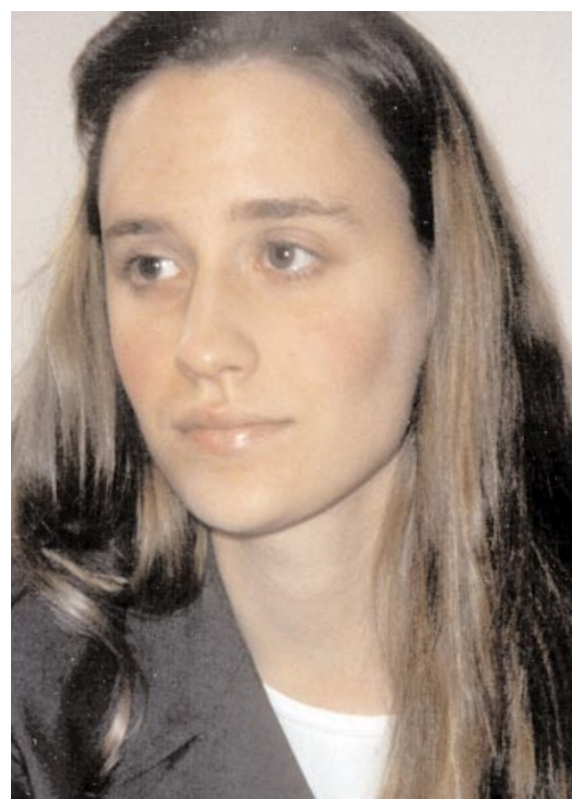

Looking ahead: Journal of Young Investigators editor-in-chief Courtney Peterson believes the quality of submissions is improving.

Typical of the new breed is the Dartmouth Undergraduate Journal of Science (DUJS) formed in 1998 at Dartmouth College in Hanover, New Hampshire, by four industrious undergrads. In addition to the online journal, a hard copy of the DUJS, which features eye-catching cover designs (see below), is produced for campus-wide distribution. The review of manuscripts is conducted completely by undergraduates.

Again, students who have published in the DUJS say they have benefited from the experience. Anura Abeyesinghe, a physics undergraduate who published on quantum entanglement, says the paper proved valuable when he applied for graduate school. "The journal is online and that made it easy for me to simply mention the website in my

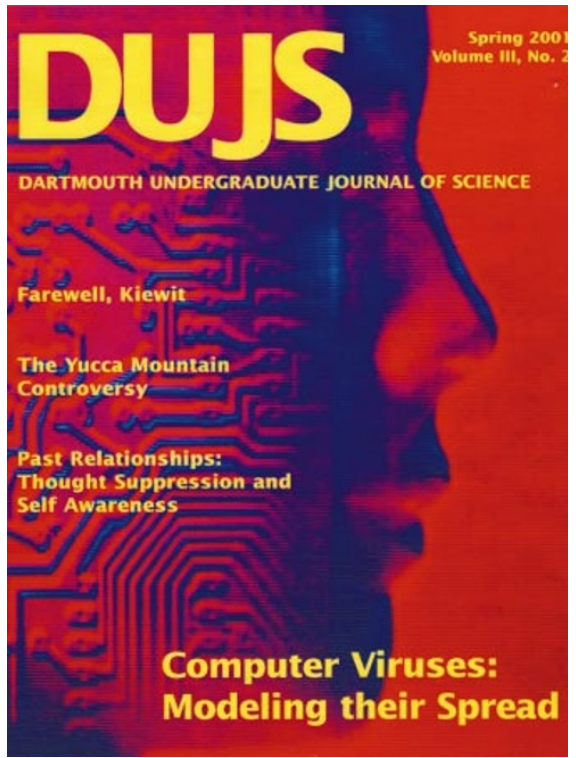

Widely read: the DUJS is on paper and online.

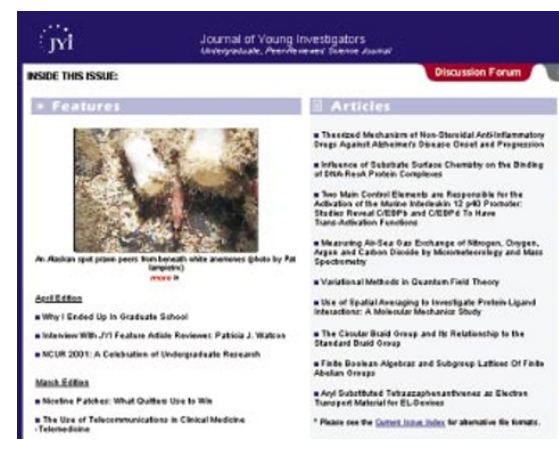

application so that the grad school people could read my article and get an idea of the kind of work I have done." He intends to study quantum information theory at either the Massachusetts Institute of Technology or the California Institute of Technology.

Other projects are subject-specific but not limited to research by students at a particular institution. The National Undergraduate Research Clearinghouse, for instance, provides an online repository for psychology papers. It was established three years ago by Brian Cronk, a professor at Missouri Western State College in St Joseph. Rather than using conventional peer review, it exercises quality control by getting faculty members to sponsor the submissions.

Encouraged by the success of current journals, others are poised to join the fray. Sinah Shah and Alex Kastor, two graduate students at the University of Pennsylvania in Philadelphia, have just launched a multidisciplinary web-based journal, the Journal of Undergraduate Study \& Independent Research. Faculty from across the United States have volunteered to serve as reviewers.

Sceptics might argue that an undergraduate journal is no substitute for a 'real' scientific publication. But influential figures believe that such journals are performing a useful function: the JYI's last editorial conference, held in February at the annual meeting of the American Association for the Advancement of Science in San Francisco, was addressed by Rita Colwell, director of the NSF. The enthusiasm of young scientists who have published in the journals also suggests that there is a real demand among undergraduates for more experience in the art of getting your science published.

Josette Chen is an intern at Nature.

Journal of Young Investigators

http://www.jyi.org

University of Toronto Medical Journal

http://www.utmj.org

Dartmouth Undergraduate Journal of Science

http://www.dartmouth.edu/ dujs

National Undergraduate Research Clearinghouse

http://clearinghouse.mwsc.edu

Journal of Undergraduate Study \& Independent Research http://www.jusir.org

Links to other undergraduate journals

http://eden.mercy.edu/upd

http://www.jyi.org/resources/ugradPubs.html 